\title{
Correction to: Feedback through emotion extraction using logistic regression and CNN
}

\author{
Mohit Ranjan Panda ${ }^{1}\left[\right.$ - Sarthak Saurav $\mathrm{Kar}^{2} \cdot$ Aakash Kumar Nanda $^{2} \cdot$ Rojalina Priyadarshini $^{2}$. \\ Susmita Panda ${ }^{3}$. Sukant Kishoro Bisoy ${ }^{2}$
}

Published online: 10 November 2021

(C) The Author(s), under exclusive licence to Springer-Verlag GmbH Germany, part of Springer Nature 2021

\section{Correction to:}

The Visual Computer https://doi.org/10.1007/s00371-021-02260-w

The publication of this article unfortunately contained mistakes. The name of one of the authors was not correct. The corrected name is given below.

Rojalina Priyadarshini.

The original article has been corrected.

Publisher's Note Springer Nature remains neutral with regard to jurisdictional claims in published maps and institutional affiliations.

The original article can be found online at https://doi.org/10.1007/ s00371-021-02260-w.

Mohit Ranjan Panda

mohit.pandafcs@kiit.ac.in

1 School of Computer Engineering, KIIT Deemed to be University, Bhubaneshwar, India

2 Department of Computer Science and Engineering, C V Raman Global University, Bhubaneshwar, India

3 Department of Electronics and Communication Engineering, Institute of Technical Education and Research, Siksha 'O'

Anusandhan, Deemed to be University, Bhubaneshwar, India 